\title{
Article
}

\section{Adsorption Behavior of Metal Ions with $\beta$-Diketone Type Chelating Agents Supported on Hydrophobized Mesoporous Silicate MCM-41}

\author{
Syunichi OSHIMA ${ }^{1 *}$, Yusuke KUMAGAI ${ }^{1}$, Yujiro WATANABE ${ }^{1}$, Kaoru FUJINAGA ${ }^{1}$, \\ Geoffrey W. SEVENS ${ }^{2}$ and Yu KOMATSU ${ }^{1}$ \\ ${ }^{1}$ Department of Applied Chemistry, College of Bioscience and Chemistry, Kanazawa Institute of Technology, 7-1 \\ Ohgigaoka, Nonoichi, Ishikawa 921-8501, Japan \\ ${ }^{2}$ Particulate Fluids Processing Centre, Department of Chemical \& Biomolecular Engineering, The University of \\ Melbourne, Victoria 3010, Australia
}

(Manuscript received May 30, 2014; Accepted July 25, 2014)

\begin{abstract}
To investigate the adsorption behavior of metal ions with $\beta$-diketone type chelating agents, thenoyltrifluoroacetone (Htta) and benzoyltrifluoroacetone (Hbfa) supported on mesoporous silicate MCM-41 that has been hydrophobized (hMCM-41) using trimethylchlorosilane was synthesized. The hexagonally arranged pore structure of MCM-41 was not significantly changed by the hydrophobic treatment and attachment of chelating agents, although the pore size, pore volume and surface area were slightly smaller than those of untreated MCM-41 as a result of the chemical modification of the surface. The amount of chelating agents adsorbed on hMCM-41 was 0.47 for Htta and $0.33 \mathrm{mmol} \mathrm{g}^{-1}$ for $\mathrm{Hbfa}$, respectively. All metal ions examined, except for $\mathrm{Cd}^{2+}$, were quantitatively adsorbed on hMCM-41 as metal complex, $\mathrm{M}(\mathrm{tta})_{2}$ or $\mathrm{M}(\mathrm{bfa})_{2}$. The order of the adsorption selectivity of the metal ions was similar to the stability constants of metal ions with Htta or Hbfa. Furthermore, most of the metal ions adsorbed onto hMCM-41 at lower $\mathrm{pH}$ compared with the results of having used MCM-41 as a support of chelating agents. This suggests that the adsorption ability of metal ions with chelating agents was improved by the hydrophobic treatment of MCM-41.
\end{abstract}

Keywords: Adsorption behavior, MCM-41, Metal ions, Chelating agents, Hydrophobic treatment

\section{Introduction}

Mesoporous silicate MCM-41 possesses hexagonally packed arrays of one-dimensional, cylindrical pores, with a uniform pore distribution and large pore volume ${ }^{1)}$. This material is most often used as an adsorbent of large organic molecules after surface functionalization. It has been reported that ordered mesoporous silicates such as MCM-41 have been functionalized with amino and thiol groups for adsorption of metal ions ${ }^{2-4)}$. Selective adsorption of some metal ions, such as $\mathrm{Hg}^{2+}, \mathrm{Cu}^{2+}$ and $\mathrm{Cr}_{2} \mathrm{O}_{7}^{2-}$, has been achieved by using the modified adsorbents based on mesoporous silicate. Moreover,
Puanngam and Unob reported that the functionalized MCM-41 showed larger binding ability for $\mathrm{Hg}^{2+}$ compared to that of the functionalized silica gel due to its uniform structure ${ }^{5)}$. In addition, adsorption behavior of divalent transition metal ions onto MCM-41 as neutral acetylacetonato complexes by adding acetylacetone in aqueous phase have also been reported ${ }^{6-9)}$. Previously we investigated adsorption behavior of metal ions with thenoyltrifluoroacetone (Htta) supported on MCM-41. From the results, it was suggested that MCM-41 could be used as a support of chelating agents used in solvent extraction systems ${ }^{10)}$. However, stability of MCM-41 is low, and the

\footnotetext{
* Corresponding author

E-mail: s.oshima@neptune.kanazawa-it.ac.jp
} 
siloxane structure of MCM-41 is damaged when MCM-41 left in a humid environment. Therefore, improvement of stability of MCM-41 in aqueous solution is necessary, and modification of the surface of MCM-41 by organic functional groups was studied to improve the stability in aqueous solutions ${ }^{7,11)}$. These surface treatments may not only be useful to improve the stability in aqueous solutions, but may influence adsorption of metal ions. In fact, the adsorption of metal ions onto modified MCM-41 was affected by the apparent hydrophobicity of metal complexes in the previous study ${ }^{7}$.

In the present study, using hydrophobized MCM-41 as a support of $\beta$-diketone type chelating agents, the adsorption behavior of metal ions with chelating agents was investigated. $\mathrm{Htta}$ and benzoyltrifluoroacetone (Hbfa) were used as $\beta$ diketone type chelating agents, and the hydrophobic treatment of MCM-41 performed by using trimethylchlorosilane. The MCM-41 was treated to make it hydrophobic and is referred to as hMCM-41. The chelating agents, Htta and Hbfa, were retained on hMCM-41, and the hMCM- 41 on which Htta or Hbfa is adsorbed (Htta-hMCM-41 or Hbfa-hMCM-41) was used as an adsorption material of metal ions. The hMCM-41 and the adsorption materials were characterized by using a powder X-ray diffraction (XRD), Fourier transform-infrared spectroscopy (FT-IR), $\mathrm{N}_{2}$ adsorption and desorption measurements. The amount of chelating agents adsorbed on hMCM-41 was determined by elemental analysis. The adsorption behavior of metal ions on the adsorption materials was investigated as a function of $\mathrm{pH}$. It is expected that the hydrophobicity of a support affect the adsorption ability of metal ions.

\section{Experimental}

\subsection{Reagents}

Cetyltrimethylammonium bromide (CTAB) and sodium silicate solution $\left(27 \% \mathrm{SiO}_{2}\right)$ were purchased from SigmaAldrich Co. LLC. The chelating agents, Htta and Hbfa, were purchased from Dojindo Laboratories. Stock solutions of metal ion were prepared by dissolving metal chloride or nitrate in water. All of the reagents were analytical or reagent grade and used without further purification. Deionized water was prepared by Milli-Q Gradient A10 MILLIPORE and used throughout.

\subsection{Synthesis of mesoporous silicate MCM-41}

The synthesis of MCM-41 was performed by a modified procedure derived from the previously reported method ${ }^{12}$. A solution of $16.4 \mathrm{~g}$ of CTAB in $69.2 \mathrm{~g}$ of water was prepared by heating to $40{ }^{\circ} \mathrm{C}$ to dissolve the CTAB. A sodium silicate solution was prepared by dissolving $19.0 \mathrm{~g}$ of sodium silicate in $40.6 \mathrm{~g}$ of water, and added to the CTAB solution. The mixture was stirred for 10 minutes at $60{ }^{\circ} \mathrm{C}$. The $\mathrm{pH}$ of mixture adjusted to $11.0-11.2$ by drop-wise addition of $3 \mathrm{~mol} \mathrm{dm}^{-3}$ sulfuric acid. The resulting gel was stirred at $65{ }^{\circ} \mathrm{C}$ for 30 minutes, transferred to Teflon cup fitted into a stainless steel pressure vessel, and heated at $100{ }^{\circ} \mathrm{C}$ for 144 hours. The solid product was filtered and washed extensively with hot water, and dried at room temperature in vacuum. The product was stirred in $1 \mathrm{~mol} \mathrm{dm}^{-3}$ hydrochloric acid-ethanolic solution (80 vol\%) at $40{ }^{\circ} \mathrm{C}$ for 24 hours in order to remove surfactant, and washed with ethanol and dried in vacuum.

\subsection{Hydrophobic treatment of the surface of MCM-41}

The hydrophobic treatment of the surface of MCM-41 was performed as follows. One gram of MCM-41 in absolute toluene was cooled at or lower than $10{ }^{\circ} \mathrm{C}$. While stirring the solution, $2.0 \mathrm{~g}$ of trimethylcholorosilane (Nacalai tesque) was added dropwise, and the mixture was stirred for $3 \mathrm{~h}$ at $25{ }^{\circ} \mathrm{C}$ and $1 \mathrm{~h}$ at $80{ }^{\circ} \mathrm{C}$ under nitrogen atmosphere. The solid product was filtered and washed with absolute toluene and ethanol. The product was dried in vacuum. The structure of obtained hMCM-41 was investigated by XRD (Rigaku, UltimaIV) with monochromatized $\mathrm{Cu} K_{\alpha}$ radiation. The infrared adsorption spectrum was obtained by FT-IR (JASCO, FT/IR-680) in a range of 4000 to $400 \mathrm{~cm}^{-1}$. The specific surface area, pore diameter and pore volume were measured by $\mathrm{N}_{2}$ adsorption and desorption measurement using Belsorp 18 apparatus (Bel Inc., Japan).

\subsection{Retention of chelating agents on hMCM-41}

In a centrifuge tube shaded with aluminum foil, $1 \mathrm{~g}$ of hMCM-41 was contacted with $10 \mathrm{~cm}^{3}$ toluene solution containing $0.5 \mathrm{~mol} \mathrm{dm}^{-3} \mathrm{Htta}$ or Hbfa for $24 \mathrm{~h}^{10}$ ). The solid and solution were separated by filtration, and the solid was washed with cold hexane. The solid product on which Htta or Hbfa adsorbed (Htta-hMCM-41 or Hbfa-hMCM-41) was dried in vacuum for $24 \mathrm{~h}$. The Htta-hMCM-41 and Hbfa-hMCM-41 were used as adsorption materials. The amount of chelating agent adsorbed on hMCM-41 was determined by elemental analysis on fluorine.

\subsection{Adsorption behavior of metal ions onto adsorption materials}

In a centrifuge tube, $0.1 \mathrm{~g}$ of adsorption material (HttahMCM-41 or Hbfa-hMCM-41) was contacted with $10 \mathrm{~cm}^{3}$ of an aqueous phase containing $1 \times 10^{-4} \mathrm{~mol} \mathrm{dm}^{-3}$ of metal ion $\left(\mathrm{Co}^{2+}, \mathrm{Ni}^{2+}, \mathrm{Cu}^{2+}, \mathrm{Zn}^{2+}, \mathrm{Cd}^{2+}\right.$ or $\left.\mathrm{Pb}^{2+}\right), 1 \times 10^{-1} \mathrm{~mol} \mathrm{dm}{ }^{-3}$ of $\mathrm{NaCl}$ as ion strength buffer and $1 \times 10^{-2} \mathrm{~mol} \mathrm{dm}^{-3}$ of $\mathrm{pH}$ buffer (chloroacetic aced, acetic acid or 2-( $N$-morpholino)ethanesulfonic acid). The buffers have no influence on the adsorption of metal ions. The mixture was agitated for 1 hour. Then, the solid and aqueous phase separated by filtration. A HORIBA F-21 pH meter with a combination glass electrode used for the measurement of the $\mathrm{pH}$ values of the aqueous phase. The concentration of metal ions in the aqueous phase was determined by ICP-AES (Varian, Vista Pro). The amount of metal ion adsorbed was calculated by subtracting the 
measured concentration from the initial concentration of metal ion in the aqueous phase.

\section{Results and Discussion}

\subsection{Characterization of the adsorption materials}

The XRD diffraction patterns for MCM-41, hMCM-41, Htta-hMCM-41 and Hbfa-hMCM-41 are shown in Fig. 1 and hexagonal lattice parameter, $\mathrm{a}_{0}$, calculated from the (100) peak is given in Table 1. The four peaks indentified at low angles in all XRD patterns are a good indication of the well-ordered hexagonally arranged pore structure typical of MCM-41 ${ }^{13)}$. The hexagonal lattice parameter are very similar to the values for MCM-41 reported previously ${ }^{9,13)}$. This result indicates that the MCM-41 structure was maintained after the hydrophobic treatment and retention of chelating agents.

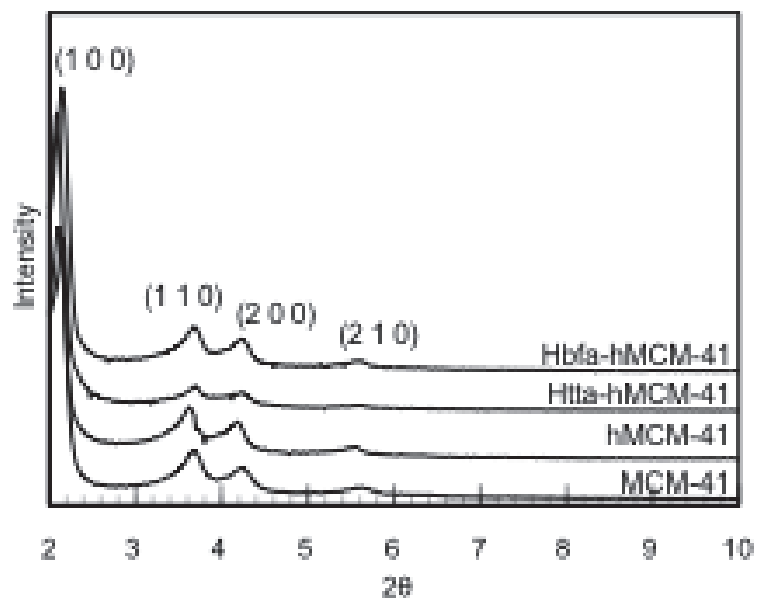

Fig. 1 XRD patterns of MCM-41, hMCM-41 and adsorption materials.

Table 1 hexagonal lattice parameter, $a_{0}(\mathrm{~nm})$

\begin{tabular}{cccc}
\hline MCM-41 & hMCM-41 & Htta-hMCM-41 & Hbfa-MCM-41 \\
\hline 4.86 & 4.90 & 4.72 & 4.77
\end{tabular}

Nitrogen adsorption and desorption isotherms for the HttahMCM-41 and Hbfa-hMCM-41 are shown in Fig. 2. The isotherms are in good agreement with typical isotherms for mesoporous materials with a regular hexagonal arrangement of cylindrical pores ${ }^{14)}$. The specific surface area, the pore diameter and pore volume of adsorption materials calculated from the $\mathrm{N}_{2}$ adsorption isotherms using the BET method and the Dollimore-Heal (DH) method are given in Table 2. The values of specific surface area and pore volume of HttahMCM-41 and Hbfa-hMCM-41 are smaller than those of hMCM-41 although the value of pore diameter was the same. This decrease is indicative of adsorption of chelating agents on the surface of hMCM-41.
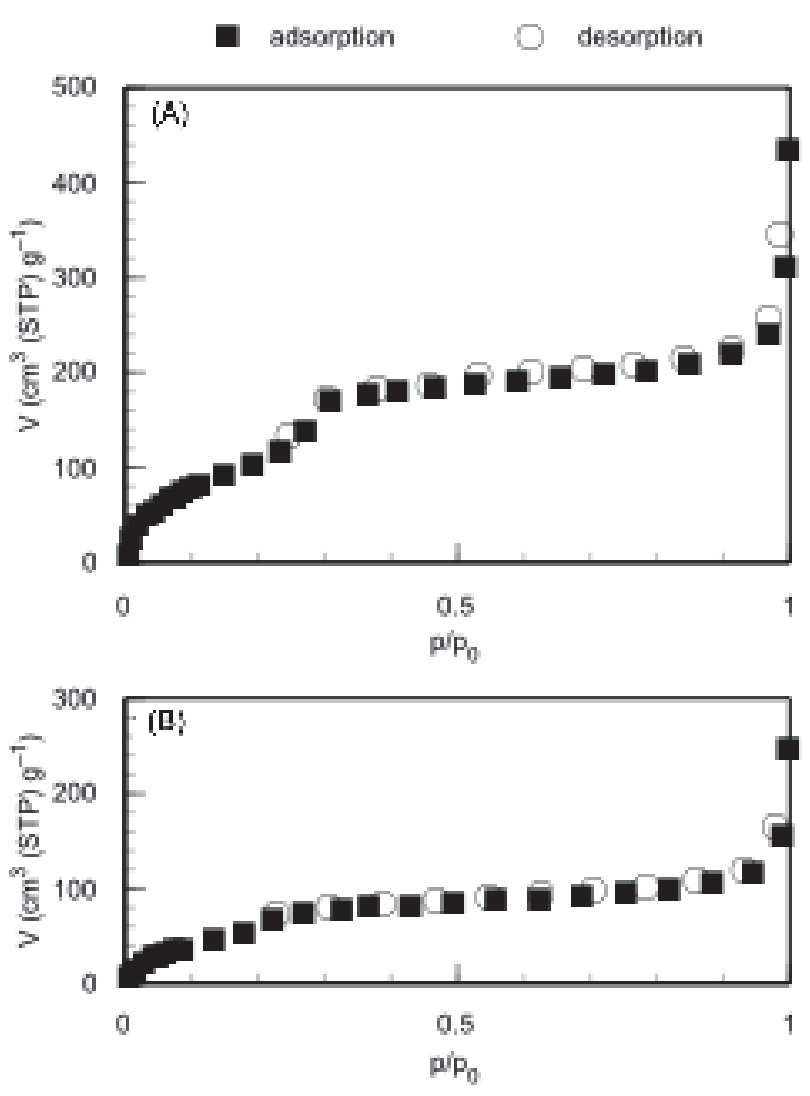

Fig. 2 Nitrogen adsorption and desorption isotherms for Htta-hMCM-41 (A) and Hbfa-hMCM-41 (B).

Table 2 structure properties of MCM-41, hMCM-41 and adsorption materials

\begin{tabular}{cccc}
\hline & $\begin{array}{c}\text { Specific surface } \\
\text { area } \\
\mathrm{m}^{2} \mathrm{~g}^{-1}\end{array}$ & $\begin{array}{c}\text { Pore diameter } \\
\mathrm{nm}\end{array}$ & $\begin{array}{c}\text { Pore volume } \\
\mathrm{cm}^{3} \mathrm{~g}^{-1}\end{array}$ \\
\hline MCM-41 & 868 & 2.42 & 0.906 \\
\hline hMCM-41 & 741 & 2.42 & 0.814 \\
\hline Htta-hMCM-41 & 469 & 2.42 & 0.545 \\
\hline Hbfa-hMCM-41 & 235 & 2.42 & 0.342 \\
\hline
\end{tabular}

The FT-IR spectra of the adsorption materials in a range of 4000 to $400 \mathrm{~cm}^{-1}$ are shown in Fig. 3. The peaks of methyl and trimethylsilyl groups were observed at 2963 and $849 \mathrm{~cm}^{-1}$, respectively. These results indicate the existence of trimethylsilyl groups on the hMCM-41 surface. However, the peaks originated from Htta and Hbfa were not observed in FTIR spectra. Because the amount of chelating agent adsorbed on hMCM-41 is small, the peaks of chelating agents in FT-IR spectra were not observed.

From the results of elemental analysis on fluorine, the amount of chelating agents adsorbed on hMCM-41 was 0.47 for Htta and $0.33 \mathrm{mmol} \mathrm{g}^{-1}$ for Hbfa, respectively. By contrast, 
that of chelating agents on MCM-41 was 0.34 for Htta and 0.15 $\mathrm{mmol} \mathrm{g}{ }^{-1}$ for $\mathrm{Hbfa}$, respectively. These results indicated that the hydrophobic treatment of surface caused the increase in the amount of chelating agents adsorbed on the support. Moreover, it was reported that the amount of Htta adsorbed on octadecyl silica gel was $0.19 \mathrm{mmol} \mathrm{g}^{-115)}$, thus the hydrophobized MCM41 has a higher retention of chelating agents than silica gel.

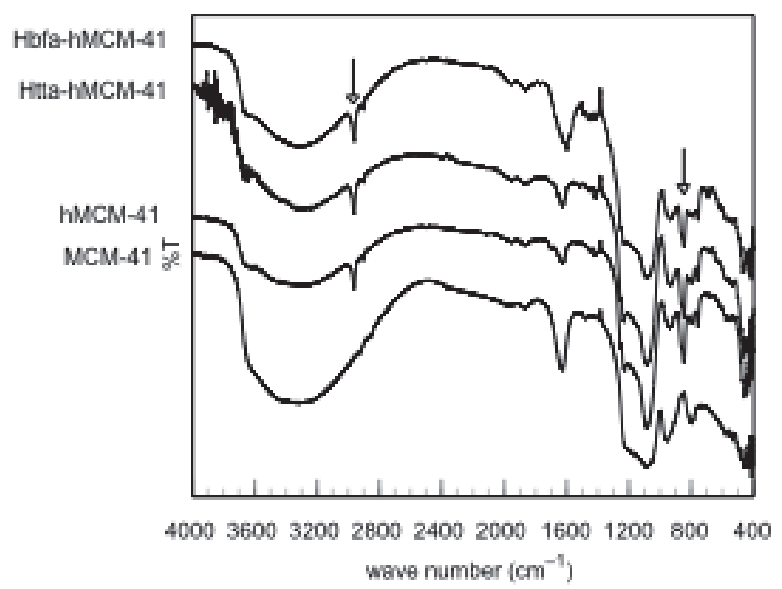

Fig. 3 FT-IR spectra of MCM-41, hMCM-41, Htta-hMCM-41 and Hbfa-hMCM-41.

\subsection{Adsorption behavior of metal ions onto adsorption materials}

The adsorption ratios (\%Adsorption) of metal ions with Htta onto hMCM-41 and MCM-41 were plotted as a function of $\mathrm{pH}$ in the aqueous phase and are shown in Fig. 4, and the results in Hbfa are shown in Fig. 5. All metal ions except for $\mathrm{Cd}^{2+}$ with Htta were quantitatively adsorbed on hMCM-41 and MCM-41. The \%Adsorption of $\mathrm{Cd}^{2+}$ in hMCM-41 and MCM-41 was about $30 \%$ at $\mathrm{pH} 6.6$ and $60 \%$ at $\mathrm{pH} 6.7$, respectively. On the other hand, all metal ions were quantitatively adsorbed on Hbfa-hMCM-41 and Hbfa-MCM-41. The order of the adsorption selectivity of $\mathrm{M}^{2+}$ was $\mathrm{Cu}^{2+}>>\mathrm{Co}^{2+}>\mathrm{Ni}^{2+}>\mathrm{Pb}^{2+} \approx$ $\mathrm{Zn}^{2+}>\mathrm{Cd}^{2+}$ for Htta-hMCM-41, $\mathrm{Cu}^{2+}>>\mathrm{Co}^{2+} \approx \mathrm{Ni}^{2+}>\mathrm{Zn}^{2+}$ $>\mathrm{Pb}^{2+}>>\mathrm{Cd}^{2+}$ for Htta-MCM-41, $\mathrm{Cu}^{2+}>>\mathrm{Ni}^{2+} \approx \mathrm{Co}^{2+}>\mathrm{Pb}^{2+}$ $>\mathrm{Zn}^{2+}>\mathrm{Cd}^{2+}$ for Hbfa-hMCM-41 and $\mathrm{Cu}^{2+}>>\mathrm{Ni}^{2+} \approx \mathrm{Co}^{2+}>$ $\mathrm{Pb}^{2+} \approx \mathrm{Zn}^{2+} \gg \mathrm{Cd}^{2+}$ for Hbfa-MCM-41. It was found that the order is similar to the order of stability constants of metal ions with $\mathrm{Htta}$ and $\mathrm{Hbfa}{ }^{16)}$. In addition, the hydrophobic treatment to the surface of MCM-41 has little affect on the adsorption selectivity of metal ions.

The metal ions studied adsorbed onto hMCM-41 in lower $\mathrm{pH}$ region than those onto MCM-41 as a support. The halfadsorption $\mathrm{pH}$ values $\left(\mathrm{pH}_{1 / 2}\right)$ defined as $\mathrm{pH}$ at $50 \%$ adsorption of metal ion in this study and shows in Table 3. The values of all studied metal ions except for $\mathrm{Zn}^{2+}$ and $\mathrm{Cd}^{2+}$ in hMCM-41 systems are smaller than those of MCM-41 systems. Thus, the adsorption ability of metal ions with $\mathrm{Htta}$ and $\mathrm{Hbfa}$ is improved by hydrophobic treatment of the surface of MCM- 41 .
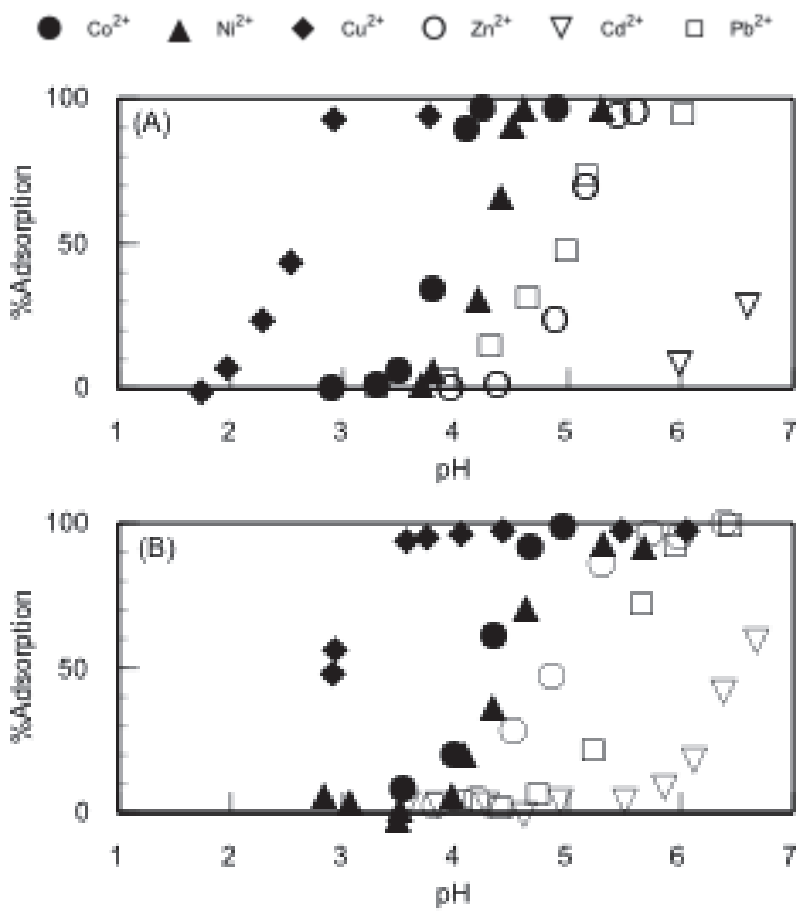

Fig. 4 Adsorption behavior of metal ions on Htta-hMCM-41 (A) and Htta-MCM-41 (B) ${ }^{10)}$.
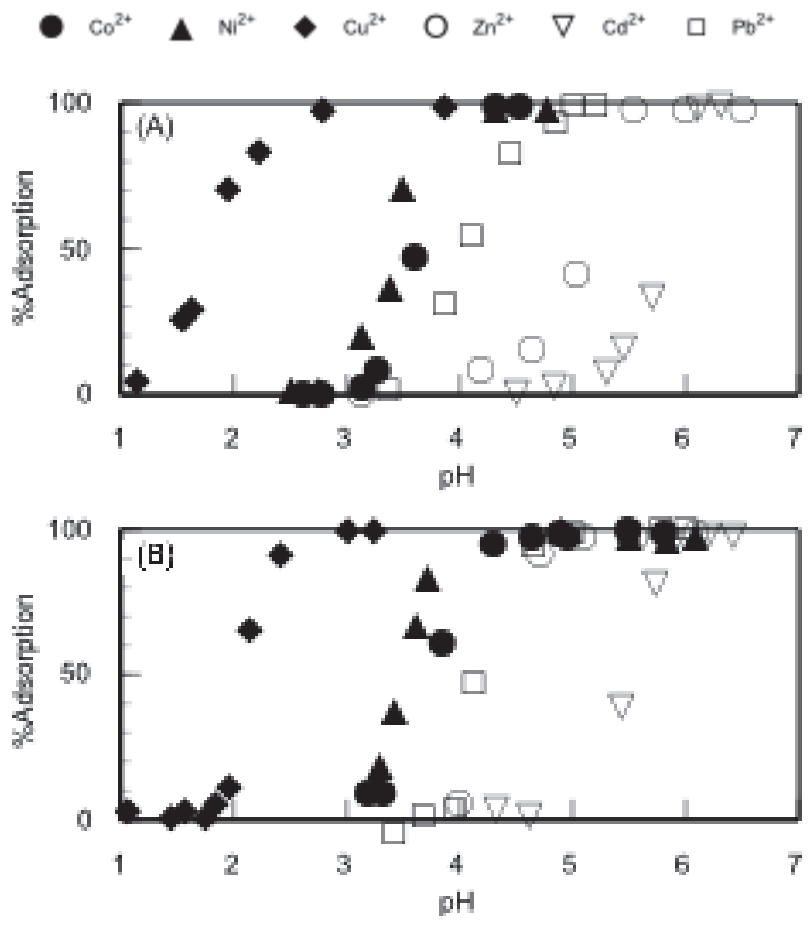

Fig. 5 Adsorption behavior of metal ions on Hbfa-hMCM-41 (A) and Hbfa-MCM-41 (B). 
Table $3 \mathrm{pH}_{1 / 2}$ values

\begin{tabular}{ccccccc}
\hline & $\mathrm{Co}^{2+}$ & $\mathrm{Ni}^{2+}$ & $\mathrm{Cu}^{2+}$ & $\mathrm{Zn}^{2+}$ & $\mathrm{Cd}^{2+}$ & $\mathrm{Pb}^{2+}$ \\
\hline Htta-hMCM-41 & 3.88 & 4.29 & 2.59 & 5.04 & $7.3^{\mathrm{a}}$ & 4.99 \\
\hline Htta-MCM-41 & 4.24 & 4.44 & 2.91 & 4.89 & 6.51 & 5.46 \\
\hline Hbfa-hMCM-41 & 3.63 & 3.42 & 1.79 & 5.11 & 5.80 & 4.05 \\
\hline Hbfa-MCM-41 & 3.72 & 3.49 & 2.09 & 4.38 & 5.52 & 4.14 \\
\hline
\end{tabular}

${ }^{\text {a }}$ Extrapolated value.

In general, Htta and $\mathrm{Hbfa}$ act as monoanionic bidentate ligand by liberating $\mathrm{H}^{+}$in solvent extraction system. In addition, it was found that two Htta molecules supported on MCM-41 in Htta-MCM-41 system released $\mathrm{H}^{+}$in the complexation and formed 2:1 complex $\left(\mathrm{M}(\mathrm{tta})_{2}\right)$ with metal ion ${ }^{10)}$. Namely, the reaction equation can be expressed as

$$
\mathrm{M}^{2+}+2 \mathrm{HA}_{(\mathrm{s})} \square \mathrm{MA}_{2(\mathrm{~s})}+2 \mathrm{H}^{+}\left(\mathrm{A}=\mathrm{tta}^{-} \text {or } \mathrm{bfa}^{-}\right),
$$

where HA and (s) represent the chelating agent adsorbed on MCM-41 and the solid phase, respectively. The distribution coefficient $\left(K_{\mathrm{d}}\right)$ was calculated for Eq. (1) as follows:

$$
\mathrm{K}_{\mathrm{d}}=\left[\mathrm{MA}_{2}\right]_{(\mathrm{s})} /\left[\mathrm{M}^{2+}\right]_{\mathrm{aq}}
$$

where $\left[\mathrm{MA}_{2}\right]_{(\mathrm{s})}$ and $\left[\mathrm{M}^{2+}\right]_{\mathrm{aq}}$ represents the moles of metal complex per $1 \mathrm{~g}$ of adsorption material and moles of metal ion per $1 \mathrm{~cm}^{3}$ of aqueous solution. From Eq. (2), the reaction equation in hMCM-41 systems was investigated by the slope analysis between logarithmic distribution coefficient $\left(\log K_{\mathrm{d}}\right)$ and $\mathrm{pH}$. The results of Htta-hMCM-41 and Hbfa-hMCM-41 are shown in Fig. 6. In all plots except for $\mathrm{Cd}^{2+}$, straight lines having the slope of about 2 were obtained. Thus, in HttahMCM-41 and Hbfa-hMCM-41 systems, two Htta or Hbfa molecules supported on hMCM-41 released $\mathrm{H}^{+}$and formed 2:1 complex with metal ion except for $\mathrm{Cd}^{2+}$. The same is true for the Htta-MCM-41 system. In contrast, the slope of the plots of $\log K_{\mathrm{d}}$ vs. $\mathrm{pH}$ for $\mathrm{Cd}^{2+}$ was $c a$. 1 in Hbfa-hMCM-41 system, although the slope analysis in adsorption of $\mathrm{Cd}^{2+}$ is difficult due to the low \%Adsorption value in Htta-hMCM-41. It indicates that one Hbfa molecule supported on hMCM-41 released $\mathrm{H}^{+}$for the adsorption of $\mathrm{Cd}^{2+}$. In the conditions which $\mathrm{Cd}^{2+}$ adsorbed on hMCM-41, this result may have been brought about by hydrolysis due to its lower stability constant 17). Cadmium ions were hardly extracted with Htta or Hbfa alone at $\mathrm{pH}$ value blow 7 in solvent extraction systems ${ }^{18,19)}$. In Htta-MCM-41 and Hbfa-MCM-41 systems, however, $\mathrm{Cd}^{2+}$ was adsorbed on MCM-41 with Htta or Hbfa. From this result, it is possible that the adsorption of $\mathrm{Cd}^{2+}$ is attributed to hydrophilicity of the surface of MCM-41. Thus, it is seemed that the hydrophobic treatment of MCM-41 caused the increase of $\mathrm{pH}_{1 / 2}$ values for $\mathrm{Cd}^{2+}$ in $\mathrm{hMCM}-41$ systems as compared with those of MCM-41. From these results, it is suggested that the adsorption ability of metal ions with chelating agents is improved by the control of the hydrophobicity of the surface of MCM-41.
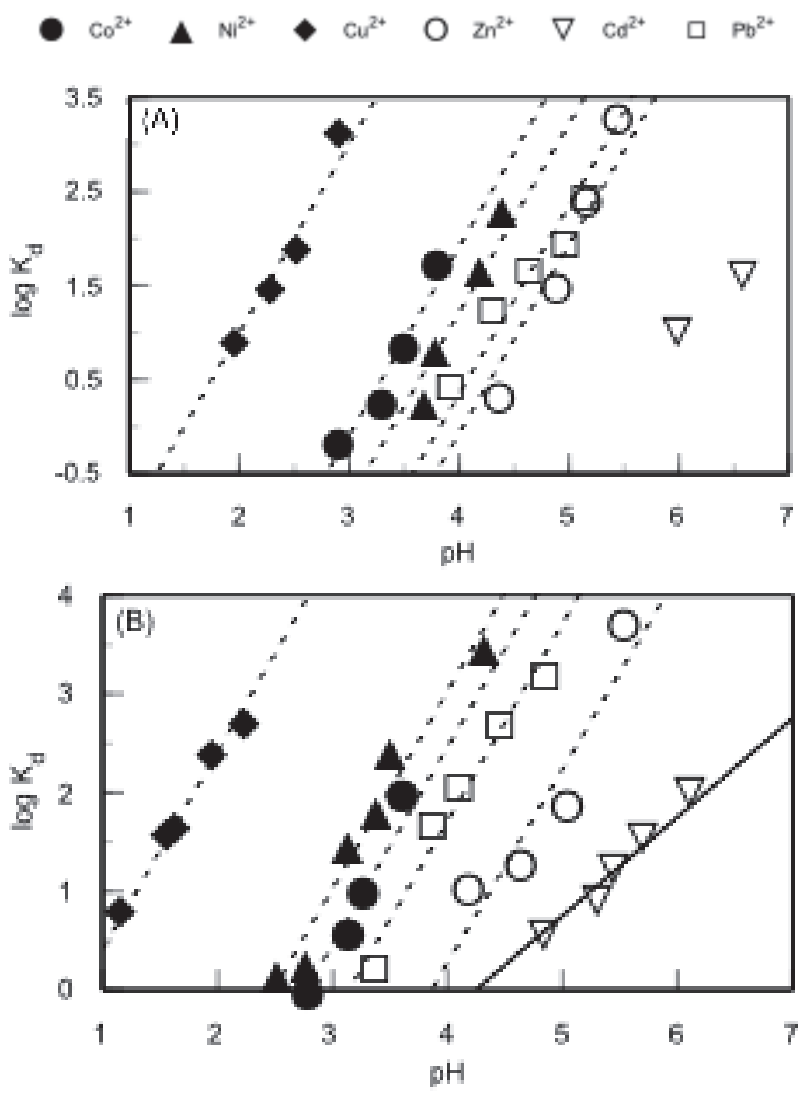

Fig. 6 Plots of $\log K_{\mathrm{d}}$ of metal ions as a function of $\mathrm{pH}$ in Htta-hMCM-41 (A) and Hbfa-hMCM-41 (B) systems.

The slope of the broken lines is $\mathbf{2}$, and the solid lines is $\mathbf{1}$.

\section{References}

1) C. T. Kresge, M. E. Leonowicz, W. J. Roth, J. C. Vartuli and J. S. Beck, Nature, 359, 710 (1992).

2) K. F. Lam, K. L. Yeung, G. Mckay, Microporous Mesoporous Mater., 100, 191 (2007).

3) Q. Yang, J. Liu, J. Yang, L. Zhang, Z. Feng, J. Zhang, C. Li, Microporous Mesoporous Mater., 77, 257 (2007).

4) X. Feng, G. E. Fryxell, L. Q. Wang, A. Y. Kim, J. Liu and K. M. Kemner, Science, 276, 923 (1997).

5) M. Puanngam and F. Unob, J. Hazardous Mater., 154, 578 (2008).

6) K. A. Northcott, S. Oshima, J. M. Perera, Y. Komatsu and G. W. Stevens, Adv. Powder Technol., 18, 751 (2007).

7) H. Oohinata, Y. Watanabe, K. Fujinaga, G. W. Stevnes, Y. Komatsu and S. Oshima, J. Ion Exchange, 21, 243 (2010).

8) A. Hokura, I. Nakai, H. Yamada, A. J. O'Connor, J. M. Perera, G. W. Stevens and Y. Komatsu, J. Ion Exchange, 14, 
173 (2003).

9) S. Oshima, J. M. Perera, K. A. Northcott, H. Kokusen, G. W. Stevens and Y. Komatsu, Sep. Sci. Technol., 41, 1635 (2006).

10) S. Oshima, H. Nakayama, M. Iwata, M. Iiyama, G. W. Stevens and Y. Komatsu, J. Ion Exchange, 21, 241 (2010).

11) Y. Watanabe, K. Miyakawa, K. Fujinaga, S. Oshima and Y. Komatsu, J. Ion Exchage, 21, 283 (2010).

12) K. J. Edler, J. Dougherty, R. Durand, L. Iton, G. Kirton, G. Lockhart, Z. Wang, R. Withers and J. W. White, Colloids Surfaces A Physicochemical and Engineering Aspects, 102, 213 (1995).

13) M. Broyer, S. Valange, J. P. Bellat, O. Bertrand, G. Weber and Z. Gabelica, Langmuir, 18, 5083 (2002).
14) P. J. Branton, P. G. Hall and K. S. W. Sing, J. Chem. Soc. Chem. Commun., 16, 1257 (1993).

15) M. Iiyama, S. Oshima, H. Kokusen, M. Sekita, S. Tsurubou and Y. Komatsu, Anal. Sci., 20, 1463 (2004).

16) G. K. Schweitzer and D. R. Randolph, Anal. Chim. Acta, 26, 567 (1962).

17) K. L. Cheng, K. Ueno and T. Imamura, "CRC Handbook of Organic Analytical Reagents, $2^{\text {nd }}$ Edition”, CRC Press, Florida (1992), p. 111.

18) M. Billah and T. Honjo, Fresenius J. Anal. Chem., 357, 61 (1997).

19) M. Sudersanan and A. K. Sundaram, Proc. Indian Acad. Sci., 85 A (2), 75, (1977). 